\title{
EFFECT OF THERMO-MECHANICAL CYCLING ON THE SHEAR BOND STRENGTH OF PORCELAIN TO MILLED AND CAST COBALT-CHROMIUM ALLOYS
}

\author{
Rasha Sayed Asaad*
}

\begin{abstract}
Statement of problem: Most of the failures in metal-ceramic restorations occurs at the interface between the two materials. For long term clinical performance, these restorations should have adequate bond strength between metal and ceramic. Few data is available in regards to the metal-ceramic bond strength of Cobalt Chromium (Co-Cr) alloys fabricated by computer aided designing design/computer aided manufacturing CAD/CAM technology.
\end{abstract}

Purpose of the study: The purpose of this in vitro study was to explore the influence of $\mathrm{Co}-\mathrm{Cr}$ fabrication techniques on shear bond strength of porcelain to milled and cast $\mathrm{Co}-\mathrm{Cr}$ alloys and to evaluate failure mode with \& without thermo-mechanical cycling.

Materials \& Methods: A total of 20 disc samples (10 mm diameter x $4 \mathrm{~mm}$ thickness) were fabricated of Co-Cr alloy and divided into two groups (10 discs each) according to their fabrication technique: Group I: fabricated by CAD/CAM milling and Group II: fabricated by conventional casting. Then porcelain build up for all discs (10 $\mathrm{mm}$ diameter x $2 \mathrm{~mm}$ thickness) was done using feldspathic porcelain. Each group was subdivided according to discs' exposure to thermomechanical cycling into two sub-groups (5 discs each). Sub-group A : without thermo-mechanical cycling and Sub-group B: with thermo-mechanical cycling. All the disc samples were subjected to the shear bond strength (SBS) test and the failure mode was investigated under digital microscope at $40 \mathrm{X}$. Data were statistically analyzed using Independent sample t-test and Two-way ANOVA test $(\mathrm{P} \leq 0.05)$.

Results: The results showed that the fabrication techniques were statistically insignificantly affecting the SBS of both CAD/CAM milled and conventional casting groups. Regarding the thermo-mechanical cycling, the CAD/CAM milled and conventional casting groups without thermo-mechanical cycling showed a statistically significantly higher SBS than those with thermomechanical cycling. Failure mode was mixed type for all disc samples.

Conclusions: Fabrication technique of Co-Cr alloy had no significant effect on SBS. Thermomechanical cycling of milled and cast Co-Cr samples significantly affecting SBS with the superiority of the non-thermo-mechanical cycled samples. All the tested samples showed SBS values within the clinically acceptable levels. CAD/ CAM fabricated Co - Cr may be considered a promising alternative to conventional cast $\mathrm{Co}-\mathrm{Cr}$ for metal ceramic prosthesis in terms of SBS.

KEY WORDS: Milled, cast, Cobalt Chromium, shear bond strength, thermo-mechanical cycling

* Oral and Maxillofacial Prosthodontic Department, Faculty of Dentistry, King Abdulaziz University, Jeddah, Kingdom of Saudi Arabia 


\section{INTRODUCTION}

Although in modern dentistry over the last 20 years the usage of all-ceramic materials in fixed prosthodontics has considerably grown, as clinically analyzed, it was found that most of crowns and fixed partial dentures (FPDs) throughout the world are still made of metal-ceramic as these restorations have excellent clinical results due to their low clinical failure (5-year cumulative failure of 4.4\%), compared to $6.7 \%$ in all-ceramic restorations. ${ }^{[1]}$

Metal-ceramic (MC) FPDs merge the high strength, longevity and marginal fit of the cast metal together with the superior esthetics of ceramic materials. Therefore, dental rehabilitation could be fulfilled through both esthetic and functional factors relying on the materials chosen. ${ }^{[2]}$ Moreover, MC restorations are still indicated where all-ceramic cannot function; as in case of increased occlusal load, limited inter-arch space (which limits the thickness of the connectors), increased span length and full-arch prosthesis. ${ }^{[3]}$

Owing to the high cost of precious alloys and the progress made in ceramic technology, base metal alloys were selected as infrastructure materials for FPDs for their excellent strength and for being economically reasonable. ${ }^{[4]}$ So different base metal alloys as nickel-chromium (Ni-Cr), titanium (Ti), and $\mathrm{Co}-\mathrm{Cr}$ are commercially available in the market. ${ }^{[5]}$

In prosthodontics, $\mathrm{Co}-\mathrm{Cr}$ alloys have been selected as a substitution for patients that show allergic reactions to $\mathrm{Ni}$. Co-Cr alloys are worldwide used in prosthodontics due to their superior marginal fit, biocompatibility, and non-existence of allergic reactions. Furthermore, these alloys promote treatments of excellent quality, as they have outstanding mechanical properties: high modulus of elasticity, hardness ,tensile strength, corrosion resistance, wear resistance, and heat resistance. ${ }^{[6,7]}$

$\mathrm{Co}-\mathrm{Cr}$ in dentistry is fabricated through three various production technologies: lost wax casting technique, $\mathrm{CAD} / \mathrm{CAM}$ and direct metal laser sintering. The different fabrication techniques are dependent on alloys that are particularly arise for each technique used. $\mathrm{Co}-\mathrm{Cr}$ restorations are traditionally fabricated by conventional lost-wax casting which is considered the most commonly used technique for manufacturing accurate cast metal restorations due to its accessibility regarding the used equipment and low cost. ${ }^{[8]}$ The casting of base metal alloys was found to be more difficult than the noble alloys. This is due to the higher melting points and vulnerability to oxidation of base metals during casting ${ }^{[9]}$ This procedure takes a long duration and requires specific expertness for dental technicians and usually ends by defects and pores within the alloy. ${ }^{[10]}$

Recently, the development of (CAD/CAM) resulted in a major change in dental laboratories, improving quality by fabricating compatible and accountable restorations. ${ }^{[1]]} \mathrm{CAD} / \mathrm{CAM}$ fabrication technique has more time-saving in comparison to conventional casting method, which is the main cause for using computer technology in construction of different prostheses .CAD/CAM systems utilize milling tools of various sizes and shapes to mill restorations from different materials' blocks. ${ }^{[12]}$ Various materials can be milled as titanium, ceramics, different types of polymers and alloys as Co-Cr. The reason of using milling technique is to overcome some drawbacks of casting, such as porosities and flaws which can reduce the accuracy of the restorations. ${ }^{[13]}$

Selective laser melting (SLM) is a recently introduced technique in comparison to both conventional casting and $\mathrm{CAD} / \mathrm{CAM}$ techniques. It is an additional method for fabricating $\mathrm{Co}-\mathrm{Cr}$ restorations from a 3D CAD model by focusing a high-power laser beam in order to fuse fine layers of metal powder. But, SLM method needs high-cost tools and is also confined to large CAD/CAM dental industrial centers. ${ }^{[14,15]}$ 
During the past 50 years, a lot of researches and studies regarding MC FPDs failures have been developed. Goodacre et al (2003) ${ }^{[16]}$ concluded that the porcelain fracture was the major factor for failure. The decrease in FPDs survival rate after 10 years may be due to material fatigue and/or a combination of mechanical and biological factors. Veneering porcelain chipping or fracture is one of the most common complication associated with MC restorations. The mechanical failures of these restorations are often a multi-factorial phenomenon and the factors may also vary depending on the type of fracture that has occurred. When the restoration is subjected to excessive stresses, the possibility of failure due to fatigue and crack propagation could rise, resulting in fractures that could occur either within porcelain or at the metal-porcelain interface. ${ }^{[17]}$

Adhesion of porcelain to the metal substructure is considered the most important factor in the clinical durability of porcelain fused to metal (PFM) restorations. Bonding of porcelain to metal is an important point to be considered for the success of the restoration. This bonding between metal and porcelain is believed to be achieved by the micromechanical bond, slight mismatching in coefficient of thermal expansion, van der Waals forces, and mainly the amount of oxidation between metal and porcelain. Failure in bonding between porcelain and metal will cause failure of the whole restoration. ${ }^{[18]}$

In dentistry, the most probably used method for evaluating bond strength between different materials is the SBS test. It is used to detect the failure type that occurs in PFM restorations with Co-Cr substructure. Several authors suggested the use of SBS test and considered it as one of the most reliable methods to assess the bond strength because it focuses the applied tension on the interface between $\mathrm{Co}-\mathrm{Cr}$ and ceramic. ${ }^{[18-20]}$ Galo et al (2010) ${ }^{[21]}$ stated that SBS values more than $25 \mathrm{MPa}$ is considered clinically acceptable.

The durability of dental prosthesis can also be affected by unfavorable conditions available intra- orally, as the masticatory cycle and the temperature changes due to the consumption of food and beverages. To simulate the intra-oral conditions, several in vitro studies have used both thermal and mechanical cycling to facilitate aging to the samples. So that during mechanical cycling, the samples are subjected to load many times, mimicking chewing cycles, while in the thermal cycling, the samples are subjected to sudden and great changes in temperature to approximate the intra-oral conditions for dental materials. ${ }^{[22-24]}$

Cemented dental prosthesis are usually subjected to the oral environmental factors that may restrict their durability since dental materials may undergo physical and chemical changes. The application of repetitive loads in mastication can cause stress concentration, and the thermal changes resulting in fatigue of different dental materials and/or at the interface between them. So, some investigators have suggested various testing procedures such as thermal or mechanical cycling in order to simulate the intra-oral conditions before testing the mechanical properties. ${ }^{[23-25]}$ In order to estimate different materials clinically, their mechanical fatigue tests should be done in a wet environment. However, the application of both mechanical and thermal cycling could be found as a more vigorous way of aging the MC restorations. ${ }^{[26]}$ As, high forces and repetitive stresses applied during the chewing cycle may result in fatigue and fracture of the materials when they are exposed to different intra-oral conditions. Various mechanical tests are crucial to evaluate the performance of these materials, to simulate physiological conditions generated by the chewing cycle and to produce more data than studies using a constant loading rate. ${ }^{[27,28]}$

This study was carried out first to evaluate PFM shear bond strength of conventionally used feldspathic porcelain to milled and cast Co-Cr alloy, then to compare them with and without thermomechanical cycling and finally evaluate the failure mode for all samples. The first null hypothesis was that SBS values between porcelain and $\mathrm{Co}-\mathrm{Cr}$ were 
independent of the fabrication technique (milling or casting). The second null hypothesis was that thermo-mechanical cycling would not affect SBS values for all samples.

\section{MATERIALS AND METHODS}

\section{Study Design}

In this in vitro study, a total of 20 disc samples (10 mm diameter $\mathrm{x} 4 \mathrm{~mm}$ thickness) were fabricated of Co-Cr alloy and divided into two groups (10 discs each) according to their fabrication technique: Group I: fabricated by CAD/CAM milling and Group II: fabricated by conventional casting. Then, porcelain build up for all discs (10mm diameter x $2 \mathrm{~mm}$ thickness) was done using feldspathic porcelain. Each group was subdivided according to discs' exposure to thermo-mechanical cycling into two sub-groups (5 discs each). Subgroup A: without thermo-mechanical cycling and Sub-group B: with thermo-mechanical cycling.

\section{Fabrication of Co-Cr dises}

\section{I) Discs fabrication by CAD/CAM technology}

Standardized ten discs were fabricated by the $\mathrm{CAD} / \mathrm{CAM}$ wet milling technique according to the following steps:

\section{a- Designing of the discs}

By the aid of the CAD software (Exocad Dental CAD,v.2016,GmbH, Darmstadt, Germany), discs were individually designed with $10 \mathrm{~mm}$ diameter and $4 \mathrm{~mm}$ thickness.

\section{b-Milling of the Discs :}

A Co-Cr blank specific for the wet milling procedure (Adentatec system soft-Blank, GmbH\& Co, Germany, /Chemical composition: (Co 61.65\%, Cr $27.75 \%$, W $8.45 \%$, Mn $0.25 \%$, Si $1.61 \%$, Fe $0.2 \%$, others $<0.1 \%$ ) with $99.5 \times 18 \mathrm{~mm}$ dimensions was used in this study. The 2-dimensional shapes of discs were digitized with CAD software (Exocad Dental CAD,v.2016,GmbH, Darmstadt, Germany).
Ten discs were milled to the designed dimensions using a 5-axis computerized numerically controlled milling machine (Yenadent D43, Istanbul turkey MFG), following the wet milling protocol according to the manufacturer's recommendations. Then the milled discs were separated using a cutting disk and sandblasted with $125 \mu$ aluminum oxide particles at 3 bar pressure following the manufacturer's instructions. After the milling process no heat treatment was performed.

\section{II) Discs fabrication by lost wax casting technique}

Ten discs (10 mm diameter x $4 \mathrm{~mm}$ thickness) were prepared with the lost wax casting. In order to standardize their diameter and thickness, all wax discs were fabricated by the CAD/CAM technology. The wax discs were designed similar to the CAD/ CAM fabricated Co-Crdiscs using the CAD software (Exocad Dental CAD,v.2016,GmbH, Darmstadt, Germany), wax patterns were milled from a casting wax blank for CAD/CAM (Huge, GmbH \& Co. $\mathrm{KG}$, Germany) using a 5-axis milling machine (vhf CAM 5-S1, camfacture AG,Germany). Milled wax discs were coated with surfactant (Aurofilm, Bego, Germany), and allowed to dry for minutes then invested (Bellavest SH \& begosal mixing liquid, Bego, 160g. powder / 29ml liquid). For the elimination of wax, the investment rings were inserted in an oven (Midtherm $200 \mathrm{MP}$; Bego) and temperature was increased to $900^{\circ} \mathrm{C}$ and held for 60 minutes. After wax elimination, the $\mathrm{Co}-\mathrm{Cr}$ alloy (Adentatec System Duro, GmbH\& Co,Germany / Chemical composition: Co $59.9 \%$, Cr $24.8 \%$, W $8.5 \%, \mathrm{Nb} 2.2 \%, \mathrm{~V} 2.2 \%$, Mo $0.95 \%$, Fe $0.1 \%$, Si $0.95 \%$ Others $\geq 0.1$ ) was cast in an induction casting machine (Fornax $35 \mathrm{HF}$ induction casting machine, 10060 S. Secondodi Pinerolo- Italy) at the manufacturer recommended casting temperature $\left(1485^{\circ} \mathrm{C}\right)$. The investment was removed by airborne particle abrasion with $125 \mu$ aluminum oxide in a sandblaster (Duoster F1 -BEGO) at 3 bar pressure and sprues were cut by carbide disks at low speed. Metal discs were cleaned with a steam cleaner. 


\section{Porcelain veneering of the $\mathrm{Co}-\mathrm{Cr}$ discs}

In order to standardize the thickness and shape of the veneering porcelain for all discs and by the aid of the CAD/CAM technology, a special CAD wax disc sample (10mm diameter x 6mm thickness) ${ }^{[29]}$ was designed similar to the CAD/CAM fabricated Co-Cr discs using the CAD software (Exocad Dental CAD,v.2016,GmbH, Darmstadt, Germany). The CAD wax disc was milled from a casting wax blank for CAD/CAM (Huge, GmbH \& Co. KG, Germany) using a 5-axis milling machine (vhf CAM 5-S1, camfacture AG,Germany). The CAD wax was milled to be used as mold former. This CAD wax disc was used to form $10 \mathrm{~mm}$ diameter and $6 \mathrm{~mm}$ thickness silicon mold, thereby providing a $2 \mathrm{~mm}$ thickness of veneering porcelain.

\section{Technique of the silicon mold formation}

The CAD wax disc (Huge, GmbH \& Co. KG, Germany ) with dimensions $10 \mathrm{~mm}$ diameter $\mathrm{x} 6 \mathrm{~mm}$ thickness was fixed on a glass slab. Then light body of Vinyle Polysiloxane impression material (3M ESPE, Imprint 3 Quick Step,U.S.) was injected around the CAD wax disc. Another glass slab was placed over the impression, under uniform pressure of a $5 \mathrm{~kg}$ weight. After complete setting of the impression material, the weight and the upper glass slab were removed leaving the CAD wax disc surrounded by the silicon mold. Then the CAD wax disc was removed from the silicon mold leaving a space with dimensions $10 \mathrm{~mm}$ diameter $\mathrm{x} 6 \mathrm{~mm}$ thickness. A sharp lancet was used to section the silicon mold into three pieces for ease of separation. After that the Co-Cr disc sample (10mm diameter $\mathrm{x}$ $4 \mathrm{~mm}$ thickness) was inserted into the space created in the silicon mold leaving a standardized $2 \mathrm{~mm}$ thickness to be filled with porcelain. ${ }^{[30]}$

\section{Porcelain build up}

Prior to their porcelain veneering, all the Co$\mathrm{Cr}$ discs were subjected to sandblasting with $125 \mu$ aluminum oxide particles for both milled and cast discs at 3 bar pressure, $20 \mathrm{~mm}$ distance and $90^{\circ}$ angle between the sandblaster's nozzle and the disc's surface following the manufacturer's recommendations. All samples were cleaned with air steam.

Porcelain was applied to all samples, according to the manufacturer's instructions, by layering technique using feldspathic porcelain that involved applications of opaque, dentin, and enamel layers (VITA VMK Master, Vita Zahnfabrik, Germany). A layer of opaque porcelain was first applied to the metal after mixing and fired at $\left(960^{\circ} \mathrm{C}\right)$ in a porcelain furnace (Programat P310 furnace,Ivoclar Vivadent,Schaan, Liechtenstein). To avoid shrinkage, another layer of opaque porcelain was mixed and applied over the discs and was fired at $\left(950^{\circ} \mathrm{C}\right)$, followed by dentin and enamel porcelain application and firing $\left(930^{\circ} \mathrm{C}\right)$ then autoglaze firing $\left(920^{\circ} \mathrm{C}\right)$. Porcelain was applied, condensed and fired according to the manufacturer's recommendations. Porcelain was fired on all discs together to standardize the procedure. In order to know the amount of shrinkage during firing, a dial caliper (6-inch stainless steel, Northern Tool) was used to assess the diameter of the porcelain before SBS testing.

\section{Testing procedures}

\section{Thermo-mechanical cycling}

Each group was randomly divided into two subgroups: one subjected to mechanical and thermal cycling, and the other one was stored in $100 \%$ humidity for $24 \mathrm{~h}$ at $37^{\circ} \mathrm{C}$ (control group) prior to the SBS test.

Thermo-mechanical cycling via cyclic loading was performed using a programmable logic controlled equipment; the newly developed four stations multimodal ROBOTA chewing simulator integrated with thermo-cyclic protocol operated on servo-motor (Model ACH-09075DC-T, AD-Tech Technology CO., LTD., Germany)

ROBOTA chewing simulator which has four chambers simulating the vertical and horizontal movements simultaneously in the thermodynamic condition. Each chamber consists of an upper 
Jackob's chuck as natural tooth antagonist holder that was tightened with a screw and the lower part was Teflon housing as sample holder. A weight of 5 $\mathrm{kg}$, which is comparable to $50 \mathrm{~N}$ of chewing force was exerted. Mechanical cycling was performed by vertically loading samples with $50 \mathrm{~N}$ for 37500 cycles at $1.6 \mathrm{~Hz} .^{[31]}$ The vertical movement was $3 \mathrm{~mm}$ (with rising speed of $90 \mathrm{~mm} / \mathrm{s}$ and descending speed of $40 \mathrm{~mm} / \mathrm{s}$ ) and the horizontal movement was $1 \mathrm{~mm}$ (with forward speed of $90 \mathrm{~mm} / \mathrm{s}$ and backward speed of $40 \mathrm{~mm} / \mathrm{s}$ ) at a torque of 2.4 N.m. Thermal cycling (3000 cycles) ${ }^{[32]}$ was carried out using thermocycler (Dual chamber, Bilgi, Turky) in distilled water at temperatures of $5^{\circ} \mathrm{C}$ and $55^{\circ} \mathrm{C}$ with a dwell time of $60 \mathrm{~s}$ at each temperature.

\section{Shear bond strength testing}

All samples were individually mounted on a computer controlled universal testing machine (Model 3345; Instron Industrial Products, Norwood, USA) with a loadcell of $5 \mathrm{kN}$ and data were recorded using computer software (Bluehill Lite; Instron Instruments). The samples were screwed in a metal holder in the lower fixed compartment of testing machine. Shearing test was done by compressive mode of load applied at metal-porcelain interface using a mono-beveled chisel shaped metallic rod

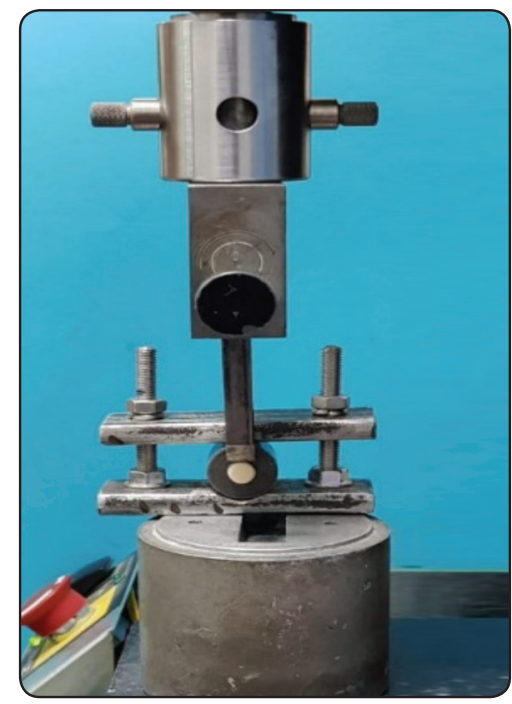

Fig. (1) A disc sample tightened in a metal holder in a universal testing machine attached to the upper movable compartment of testing machine traveling at cross-head speed of 0.5 $\mathrm{mm} / \mathrm{min}$. (Fig.1). The load required to debonding was recorded in Newton.

\section{Shear bond strength calculation:}

The load at failure was divided by bonding area to express the bond strength in $\mathrm{MPa}$ :

$$
\tau=\mathrm{P} / \pi \mathrm{r}^{2}
$$

where ; $\tau=$ shear bond strength $(\mathrm{MPa}, \mathrm{P}=$ load at failure $(\mathrm{N})$

$$
\pi=3.14 \text { and } \mathrm{r}=\operatorname{radius} \text { of } \operatorname{disc}(\mathrm{mm})
$$

\section{Failure mode analysis}

Fractured disc samples were cleaned ultrasonically and carefully examined under digital microscope (Scope Capture Digital Microscope, Guangdong, China) at a magnification of 40X to analyze their failure mode. The images were transferred to an IBM compatible personal computer with (Vertical Image J 1.43U, National Institute of Health, USA)software. There are three types of failure mode mentioned in literature: Adhesive(at metal-ceramic interface), Cohesive(in porcelain) and Mixed (mixture of adhesive and cohesive failure). ${ }^{[12]}$

\section{Statistical Analysis}

Independent sample t-test was used to compare between two groups in non-related samples.

Two-way ANOVA was used to study the effect of fabrication techniques, thermo-mechanical cycling and their interaction on mean shear bond strength.

The significance level was set at $\mathrm{P} \leq 0.05$. Statistical analysis was performed with IBM (IBM Corporation, NY, USA) SPSS Statistics Version 20 for Windows (SPSS, Inc., IBM Company).

\section{RESULTS}

The mean and standard deviations for the mean values of shear bond strength measured in(MPa) 
were calculated for each group in each test. Data were explored for normality using KolmogorovSmirnov and Shapiro-Wilk tests, data showed parametric distribution. (Table1)

TABLE (1) Descriptive statistics for Shear bond strength values of different groups and sub-groups.

\begin{tabular}{|l|c|c|c|c|c|}
\hline \multirow{2}{*}{ Variables } & \multicolumn{4}{|c|}{ Shear bond strength } \\
\cline { 2 - 6 } & $\begin{array}{c}\text { CAD/CAM } \\
\text { Milling }\end{array}$ & $\begin{array}{c}\text { Conventional } \\
\text { Casting }\end{array}$ & \multirow{2}{*}{ p-value } \\
\cline { 2 - 5 } & Mean & SD & Mean & SD & \\
\hline $\begin{array}{l}\text { Without thermo- } \\
\text { mechanical cycling }\end{array}$ & $35.77^{\text {aA }}$ & 3.83 & $39.65^{\mathrm{aA}}$ & 4.43 & $0.176 \mathrm{~ns}$ \\
\hline $\begin{array}{l}\text { With thermo-me- } \\
\text { chanical cycling }\end{array}$ & $25.87^{\mathrm{bA}}$ & 2.51 & $25.10^{\mathrm{bA}}$ & 2.93 & $0.708 \mathrm{~ns}$ \\
\hline p-value & \multicolumn{2}{|c|}{$0.001^{*}$} & $<0.001^{*}$ & \\
\hline
\end{tabular}

Means with different small letters in the same column indicate statistically significance difference, means with different capital letters in the same row indicate statistically significance difference. *; significant $(p<0.05)$; non-significant ( $p>0.05)$

\section{1- Shear bond strength results}

\section{A. Effect of fabrication techniques}

The fabrication techniques were statistically insignificantly affecting the shear bond strength of both CAD/CAM milled and conventional casting groups, it was graphically represented in (Fig. 2).

Without thermo-mechanical cycling: $\mathrm{CAD} /$ CAM milled samples recorded lower statistically insignificant shear bond strength mean value $(35.77 \pm 3.83 \mathrm{MPa})$ than those fabricated by the conventional casting technique $(39.65 \pm 4.43 \mathrm{MPa})$ where $(\mathrm{P}=0.176)$.

With thermo-mechanical cycling: $\mathrm{CAD} / \mathrm{CAM}$ milled samples recorded higher statistically insignificant shear bond strength mean value $(25.87 \pm 2.51 \mathrm{MPa})$ than those fabricated by the conventional casting technique $(25.10 \pm 2.93 \mathrm{MPa})$ where $(\mathrm{P}=0.708)$.

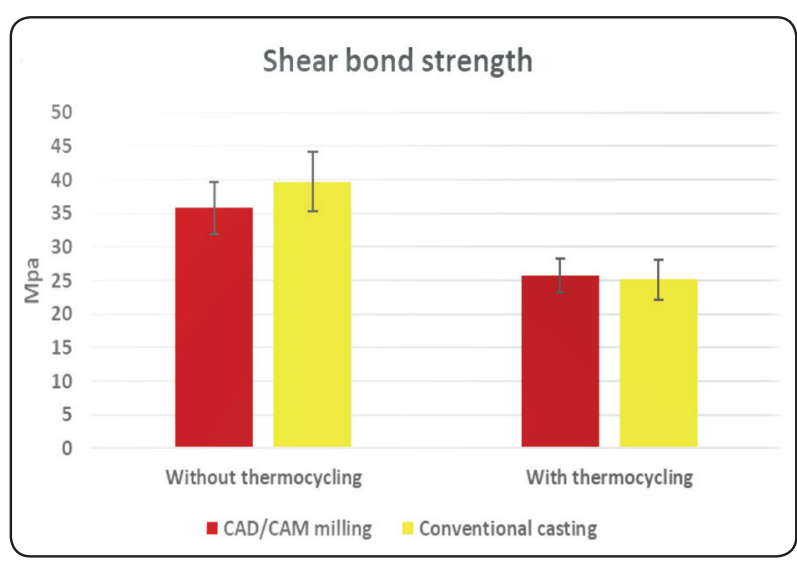

Fig. (2) A Bar chart representing the effect of fabrication technique on shear bond strength for different groups

\section{B. Effect of thermo-mechanical cycling}

Thermo-mechanical cycling was statistically significantly affecting the shear bond strength of both CAD/CAM milled and conventional casting groups, it was graphically represented in (Fig. 3).

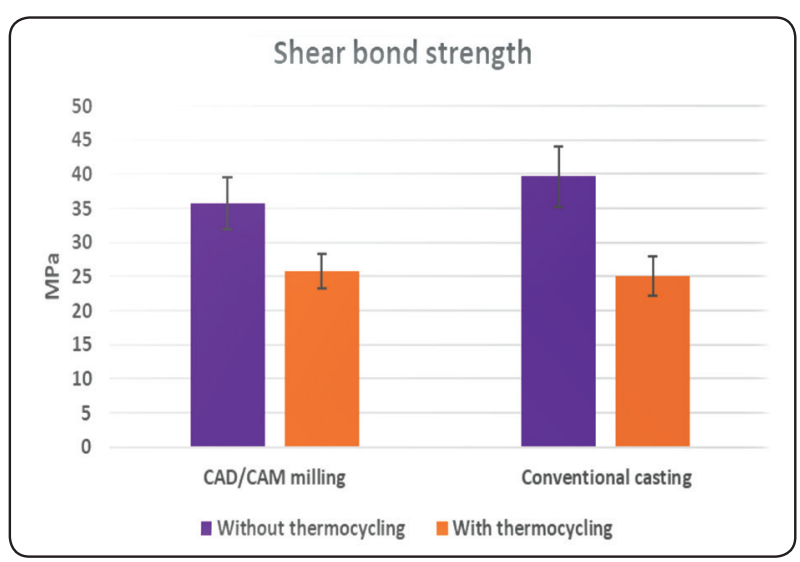

Fig. (3) A Bar chart representing the effect of thermo-mechanical cycling on shear bond strength for different groups

CAD/CAM milled samples: recorded higher statistically significant shear bond strength mean value $(35.77 \pm 3.83 \mathrm{MPa}$ ) without thermo-mechanical cycling than those with thermo-mechanical cycling $(25.87 \pm 2.51 \mathrm{MPa})$ where $(\mathrm{P}=0.001)$.

Conventional casting samples: recorded higher statistically significant shear bond strength mean value $(39.65 \pm 4.43 \mathrm{MPa})$ without thermo-mechanical cycling than those with thermo-mechanical cycling $(25.10 \pm 2.93 \mathrm{MPa})$ where $(\mathrm{P}<0.001)$. 
Two-way ANOVA results presented in (table2) showed that thermo-mechanical cycling had a statistically significant effect on mean shear bond strength. While fabrication technique had no statistically significant effect on mean shear bond strength. However, the interaction between the two variables had non-statistically significant effect on mean shear bond strength.

TABLE (2) Results of Two-way ANOVA for the effect of different variables on mean shear bond strength.

\begin{tabular}{|l|c|c|c|c|c|}
\hline Source of variation & Sum of Squares & Degree of Freedom & Means Square & $\boldsymbol{F}$-value & $\boldsymbol{P}$-value \\
\hline Thermo-mechanical cycling & 754.606 & 1 & 754.606 & 61.442 & .000 \\
\hline Fabrication Technique & 12.944 & 1 & 12.944 & 1.054 & .320 \\
\hline $\begin{array}{l}\text { Thermo-mechanical cycling } x \text { fabrica- } \\
\text { tion Technique }\end{array}$ & 25.969 & 1 & 25.969 & 2.114 & .165 \\
\hline
\end{tabular}

Degrees of freedom $=(n-1), *$ Significant at $P \leq 0.05$

\section{2- Failure Mode Results}

All the samples showed mixed type of failure with a porcelain remains attached to metal surface (Fig.4,5).

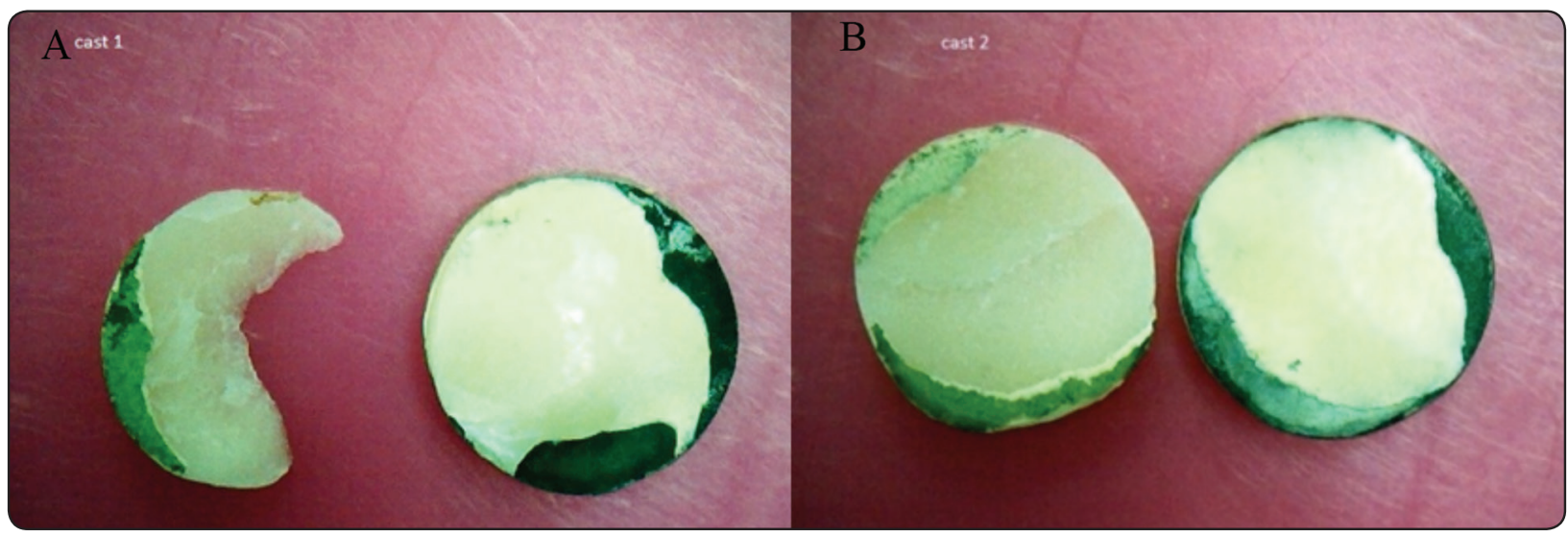

Fig.(4): A-Failure mode of cast Co-Cr discs with thermo-mechanical cycling and B-without thermo-mechanical cycling

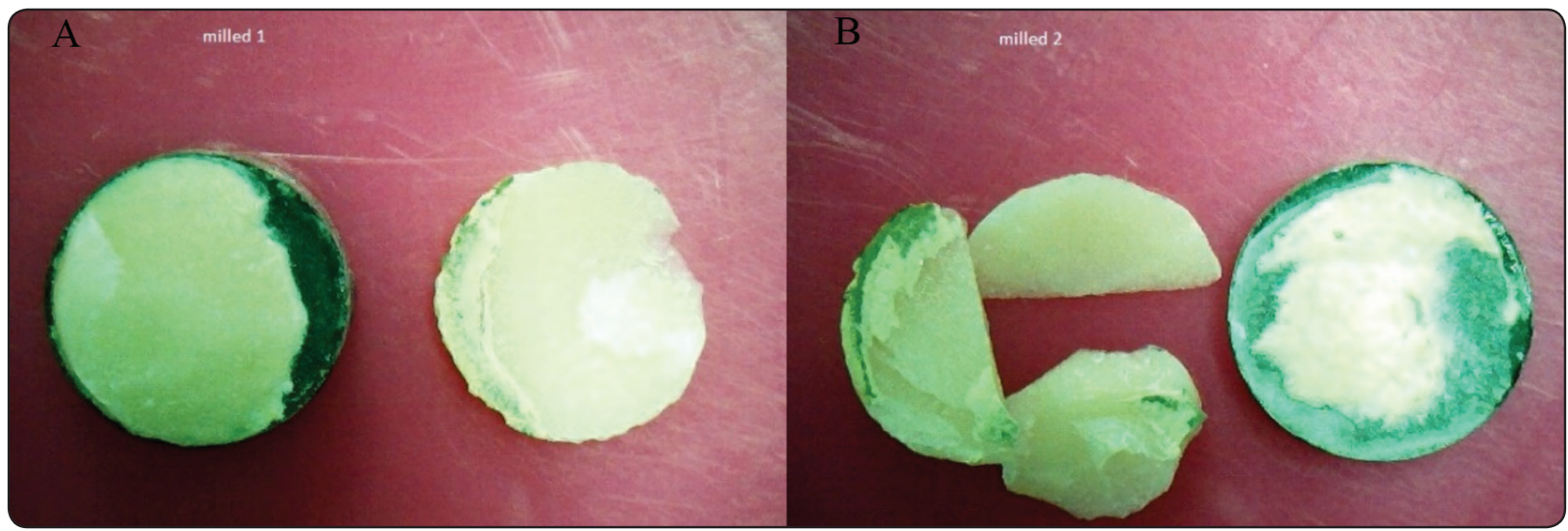

Fig.(5): A-Failure mode of milled Co-Cr discs with thermo-mechanical cycling and B- without thermo-mechanical cycling 


\section{DISCUSSION}

Even though all-ceramic crowns are the most selected and used restorations in prosthodontics, till now PFM restoration is proved to be a gold standard in prosthodontics. ${ }^{[32]}$ Metal alloys were chosen for cores and frameworks in FPDs for their high strength properties and their ability to reinforce the veneering porcelain. ${ }^{[33,34]}$ Previous clinical studies showed that the clinical longevity of PFM restorations ranges between 10-20 years or even more and that the causes of their variation are always other than mechanical failure of the prostheses. ${ }^{[20,35,36]}$

Metal-ceramic FPDs are clinically evaluated by mechanical tests, which affect the bonding between metal substrate and ceramic. The quality of MC bond has been frequently investigated. For clinical longevity the use of PFM restorations have to conform to certain demands such as biocompatibility, $\mathrm{MC}$ bond strength and corrosion resistance. ${ }^{[37,38]}$

This study evaluated the SBS of PFM samples constructed through different fabrication techniques of Co-Cralloy: CAD/CAM milling and conventional casting techniques. Some studies were done to test SBS between porcelain and $\mathrm{Co}-\mathrm{Cr}$ regarding the method of fabrication. ${ }^{[18-20]}$

The CAD/CAM milling of metallic restorations was recently introduced with the evolution of special metal blanks that have been constructed in an advanced method. CAD/CAM milling usually uses tools to cut the block to the planned shape and are controlled by a computerized system. Milling decreases pores and flaws which occurred during the conventional casting process as the Co-Cr blanks are manufactured in highly standardized conditions, also the cutting efficiency of the milling tools allows for the precision of fabricated samples. ${ }^{[39]}$ For these reasons $\mathrm{CAD} / \mathrm{CAM}$ fabricated technique of $\mathrm{Co}-\mathrm{Cr}$ was selected in this study.
Several testing procedures were used in researches in order to evaluate the bond strength between metal and ceramics, such as the tension ${ }^{[25]}$, SBS ${ }^{[12,19]}$, flexural and three-point bending. But still few data in the literature regarding the most appropriate test to assess the bond strength between these two materials. ${ }^{[20,40,41]}$ However, some authors found that the SBS test is the most reliable method to measure bond strength between the two materials. ${ }^{[6,12,19,22]}$ The predominant stress in the SBS test is shear stress, while in the 3-point bending test; tensile stress prevails. So the test chosen in this study is the SBS test which was in accordance with Della Bona and Van Noort(1995) ${ }^{[42]}$, Valandro et al (2008) ${ }^{[18]}$, Joias et al (2008) $)^{[22]}$, and Haselton et al $(2001)^{[43]}$ who reported that the SBS test has two priorities over other testing procedures for dental materials as it decreases the degree of involvement of operators in the preparation of samples, and that the failure of any sample is promptly obvious after testing (other tests need grinding or cutting first).

To duplicate the intra-oral conditions, many researches have used both thermal and mechanical cycling. ${ }^{[40,44,45]}$ The aim of mechanical cycling is to investigate the repetition of the chewing forces, to discover the survival time of different restorative materials. So it was found that cracks or wear surfaces can cause impairment of the material. ${ }^{[46]}$ Thermal cycling with temperature fluctuations produces repeated stresses that adversely affect the adhesion between metal and ceramic. ${ }^{[41]}$ Heintza et al (2016) ${ }^{[47]}$ informed that thermo-mechanical cycling can be used to evaluate the behavior of such materials when they are subjected to thermal and mechanical stress and that cyclic loading is a reliable factor for the clinical durability of PFM restorations than static loading. The chewing simulator is an appropriate and costeffective equipment to test PFM restorations for fatigue resistance. The testing procedure using chewing simulator can be applied to different layered prostheses as ceramic on metal, ceramic on zirconia and monolithic ceramic materials. ${ }^{[6]}$ So, in-order to simulate the intra-oral conditions, 
thermo-mechanical cycling with natural tooth antagonist was carried out in the present study.

In this research, to minimize variations inherent to any manual process, the wax patterns for the Co$\mathrm{Cr}$ discs fabricated by the conventional casting were constructed by the CAD/CAM technology similar to previous researches ${ }^{[6,7,14]}$ who found that $\mathrm{Co}-\mathrm{Cr}$ samples obtained from lost wax casting procedure using CAD/CAM wax patterns had better marginal fit and $\mathrm{MC}$ bond than those obtained from manually fabricated wax patterns. Additionally, this was in agreement with Joias et al (2008) ${ }^{[22]}$ who suggested that $\mathrm{Co}-\mathrm{Cr}$ alloys fabricated using traditional lost wax casting procedure with conventional wax patterns has less bonding with porcelain.

Conventionally used feldspathic porcelain was selected for layering as it is the most widely used veneering porcelain in combination with metals. In order to standardize the porcelain build up for all samples, a CAD/CAM milled wax disc with $10 \mathrm{~mm}$ diameter and $6 \mathrm{~mm}$ thickness was used thereby providing a $2 \mathrm{~mm}$ thickness of veneering porcelain. ${ }^{[29]}$

Regarding the effect of the fabrication technique on the SBS values, the results of this study support the acceptance of the first null hypothesis which stated that no differences would be found in SBS values with the milled or cast $\mathrm{Co}-\mathrm{Cr}$ groups. There was no statistically significant difference between CAD/CAM milling and conventional casting groups. Which might be due to that the lost wax casting of $\mathrm{Co}-\mathrm{Cr}$ discs were done using $\mathrm{CAD} /$ CAM milled wax to overcome the disadvantages of manual fabricated wax discs. Also the grain size of the particles used for airborne-particle abrasion and the air pressure used can be considered as factors affecting the results. In the present study the same pressure of 3 bar and the same grain size of airborne-particle abrasion were used according to the alloy manufacturer's suggestions. The angle and distance of the nozzle during the surface treatment are additional factors that might affect the surface structure. ${ }^{[40]}$ So all these factors were stan- dardized in this study. The results were consistent with Serra-Prat et al (2014) ${ }^{[15]}$ who found insignificant difference in MC SBS between Co-Cr restorations fabricated by lost wax casting method and the $\mathrm{CAD} / \mathrm{CAM}$ fabricated $\mathrm{Co}-\mathrm{Cr}$ restorations. Also, the current results were in agreement with Lee et al $(2015)^{[6]}$ who observed that Co-Cr alloy fabricated with $\mathrm{CAD} / \mathrm{CAM}$ technology had similar bond strength to porcelain as the $\mathrm{Co}-\mathrm{Cr}$ alloy fabricated with conventional casting technique using $\mathrm{CAD} /$ CAM wax. But these present results were not in agreement with Wang et al (2016) ${ }^{[48]}$ who found significant differences in MC bond strength between cast and milled groups with higher values for milled group which may be due to the difference in the bond strength test used in both studies as in their study 3-point bend test was performed.

On the other hand, results of the present study support rejection to the second null hypothesis which stated that SBS values would not be affected by thermo-mechanical cycling. As the results of this study showed that SBS for the thermo-mechanical cycled cast and milled samples was statistically significantly lower than SBS values for the nonthermo-mechanical cycled samples. Also, the results showed that after thermo-mechanical cycling, the CAD/CAM milled group exhibited lower rate of decrease in SBS than the conventional casting group. The resulted decrease in SBS of both groups might be due to mechanical cycling the causes dynamic fatigue at $\mathrm{MC}$ interface in a simulated oral environment. Additionally, thermal cycling with its successive temperature changes during water immersion, induces repeated stress that weakens the bond between metal and ceramic, due to the difference between these materials' coefficients of thermal expansion leading to different rate of expansion/contraction of the two materials which could affect SBS. ${ }^{[41]}$

Regarding the effect of thermo-mechanical cycling on SBS values, the results of current study were in agreement with Vojdani et al (2012) ${ }^{[50]}$ who evaluated the effect of thermo-mechanical cycling 
on the bond strength of a ceramic to three $\mathrm{Co}-\mathrm{Cr}$ and two Ni-Cr alloys, and observed that thermomechanical fatigue condition has decreased the bond strength of $\mathrm{Ni}-\mathrm{Cr}$ and $\mathrm{Co}-\mathrm{Cr}$ alloys to the ceramic. However, they proved that the MC samples still have adequate bond strength for clinical performance of the restorations. Also, the results were in accordance with Serra-Prat et al (2014) ${ }^{[15]}$ who compared the SBS of porcelain to cast, laser sintered and milled Co-Cr alloys, and found that SBS values were decreased for all the thermo-cycled samples and significantly so for the cast and milled samples. The results obtained by Lombardo et al $(2010)^{[20]}$, Oliveira de Vasconcellos et al (2011) ${ }^{[40]}$, Oyafuso et al (2008) $)^{[41]}$ and Fischer et al (2009) ${ }^{[49]}$ were also similar to that reported in this research regarding reduction in the SBS values after thermomechanical cycling with significant differences. On the contrary, Antanasova et al (2018) ${ }^{[51]}$ and Trindade et al (2014) ${ }^{[52]}$ concluded that thermomechanical cycling decreased the bond strength for the ceramic to $\mathrm{Co}-\mathrm{Cr}$ specimens but without statistically significant differences. This might be due to the difference in the thermodynamic protocols used in these two studies in comparison to the thermodynamic protocol used in this present study.

As there is no association between SBS values and the fabrication techniques, in addition to the lower rate of SBS reduction of CAD/CAM milled group after thermo-mechanical cycling. So the $\mathrm{CAD} / \mathrm{CAM}$ milled $\mathrm{Co}-\mathrm{Cr}$ restorations can be used as an alternative to lost wax cast restorations due to their advantages over the casting fabrication technique in reducing the porosities and flaws induced from the casting one which can affect the quality of final restorations. ${ }^{[39]}$

In most literatures it was accepted that the ISO 9693 recommended the SBS value for metal-ceramic restorations to be at least $25 \mathrm{MPa} .{ }^{[22]}$ The SBS values obtained in this study for both thermo-mechanical cycled and non-thermo-mechanical cycled samples were higher than this recommended value.
Analysis of the failure mode in this study revealed that all of the disc samples presented mixed failure which consists of both adhesive failure between metal and porcelain, and cohesive failure in the porcelain, with a porcelain fragment in contact to the metal. These results were in accordance with those of Oliveira de Vasconcellos et al (2011) ${ }^{[0]}$ who investigated the effect of thermo-mechanical cycling on the bond strength of a ceramic fused to both Co-Cr alloy and gold alloy with prevalence of mixed failure for both alloys. Also the mixed failure resulted in this research was the same as observed in the study done by Suliman and Styern (2013). ${ }^{[33]}$ Additionally, according to Papazoglou and Brantley $(1998)^{[54]}$, the mixed type of failure allow the existence of excellent bond strength between metal and ceramic.

According to the results observed in this study, mixed failure was found in all groups, while the SBS values regarding thermo-mechanical cycling were statistically significantly different among these groups which was in agreement with many authors ${ }^{[12,20,22,33]}$ who have investigated the relationship between the bond strength and failure mode and informed that there is no direct relationship between failure mode and metal ceramic SBS.

The limitations of this study include being an in-vitro investigation which cannot reproduce all clinical parameters. So longitudinal clinical trials are still needed to evaluate the behavior of the differently fabricated PFM restorations clinically.

\section{CONCLUSIONS}

Within the limitations of the present study the following conclusions can be drawn:

1. Fabrication technique of Co-Cr alloy had no significant effect on SBS.

2. Thermo-mechanical cycling of milled and cast Co-Cr samples significantly affecting SBS with the superiority of the non-thermo-mechanical cycled samples. 
3. All the tested samples showed SBS values within the clinically acceptable levels.

4. CAD/CAM milled Co-Cr may be considered a promising alternative to the conventional cast $\mathrm{Co}-\mathrm{Cr}$ for metal-ceramic prosthesis in terms of SBS.

\section{REFERENCES}

1. Pjetursson BE, Sailer I, Zwahlen M, Hämmerle CH. A systematic review of the survival and complication rates of all-ceramic and metal-ceramic reconstructions after an observation period of at least 3 years. Part I: Single crowns. Clin Oral Implants Res 2007;18:73-85.

2. Ozcan M, Niedermeier W. Clinical study on the reasons and location of the failures of metal-ceramic restorations and survival of repairs. Int J Prosthodont 2002;15:299-302.

3. Johanson M, Mosharraf S, Karlsson S, Carlsson GE. A dental laboratory study of the dimensions of metal frameworks for fixed partial dentures. Eur J Prosthodont Res Dent 2000;8:75-78.

4. Eliasson A, Arnelund CF, Johansson A: A clinical evaluation of cobalt-chromium metal-ceramic fixed partial dentures and crowns: a three- to seven-year retrospective study. J Prosthet Dent 2007;98:6-16.

5. Sailer I, Pjetursson BE, Zwahlen M, Hämmerle CH. A systematic review of the survival and complication rates of all-ceramic and metal-ceramic reconstructions after an observation period of at least 3 years. Part II: fixed dental prostheses. Clin Oral Implants Res 2007;18:114-116.

6. Lee DH, Lee BJ, Kim SH, Lee KB. Shear bond strength of porcelain to a new millable alloy and a conventional castable alloy. J Prosthet Dent 2015;113:329-335.

7. Sallam HI. Influence of Cobalt Chromium framework fabrication techniques on marginal accuracy and fracture behavior of implant supported metal ceramic bridges. EDJ 2017;63:337-350.

8. T. Dikova. Properties of Co-Cr dental alloys fabricated using additive technologies. Biomaterials in Regenerative Medicine. InTech Open Scien 2018:141-159.

9. Rosenstiel SF, Land MF, Fujimoto J. Contemporary fixed prosthodontics. 4th ed. Barcelona: Elsevier; 2009: 748752 and 606-610.

10. Li J, Chen C, Liao J, Liu L, Ye X, Lin S, Ye J. Bond strengths of porcelain to cobalt-chromium alloys made by casting, milling, and selective laser melting. J Prosthet Dent 2017; 118: 69-75.
11. Yoon TH, Madden JC, Chang WG. A technique to restore worn denture teeth on a partial removable dental prosthesis by using ceramic onlays with CAD/CAM technology. J Prosthet Dent 2013;110:331-332.

12. Akova T, Ucar Y, Tukay A, Balkaya MC, Brantley WA. Comparison of the bond strength of laser-sintered and cast base metal dental alloys to porcelain. Dent Mater 2008;24: 1400-1404.

13. Strub JR, Rekow ED, Witkowski S. Computer-aided design and fabrication of dental restorations: current systems and future possibilities. J Am Dent Assoc 2006;137:1289-1296.

14. Örtorp A, Jönsson D, Mouhsen A, Vult von Steyern P. The fit of cobalt-chromium three-unit fixed dental prostheses fabricated with four different techniques: A comparative in vitro study. Dent Mater 2011; 27: 356-363.

15. Serra-Prat J, Cano-Batalla J, Cabratosa-Termes J, FiguerasÀlvarez O. Adhesion of dental porcelain to cast,milled, and laser-sintered cobalt-chromium alloys: Shear bond strength and sensitivity to thermocycling.J Prosthet Dent 2014;112:1-6.

16. Goodacre CJ, Bernal G, Rungcharassaeng K, Kan JY. Clinical complications in fixed prosthodontics. J Prosthet Dent 2003;90:31- 41 .

17. Dundar M, Ozcan M, Gokce B, Comlekoglu E, Leite F, Valandro LF. Comparison of two bond strength testing methodologies for bilayered all-ceramics. Dent Mater 2007;23:630-636.

18. Valandro LF, Ozcan M, Amaral R, Vanderlei A, Bottino MA. Effect of testing methods on the bond strength of resin to zirconia-alumina ceramic: microtensile versus shear test. Dent Mater 2008;27:849-855.

19. Bondioli IR, Bottino MA. Evaluation of shear bond strength at the interface of two porcelains and pure titanium injected into the casting mold at three different temperatures. J Prosthet Dent 2004; 91:541-547.

20. Lombardo GH, Nishioka RS, Souza RO, Michida SM, Kojima AN, Mesquita AM, Buso L . Influence of surface treatment on the shear bond strength of ceramics fused to cobalt chromium. J Prosthodont 2010;19:103-111.

21. Galo R, Frizzas DG, Rodrigues RC, Ribeiro RF, De Mattos MD. Shear bond strength of dental ceramics to cast commercially pure titanium. Braz J Oral 2010;9:362-365.

22. Joias RM, Tango RN, Junho de Araujo JE, De Araujo MA, Ferreira Anzaloni Saavedra Gde S, Paes-Junior TJ, Kimpara ET. Shear bond strength of a ceramic to $\mathrm{Co}-\mathrm{Cr}$ alloys. J Prosthet Dent 2008;99:54-59. 
23. Tróia MG Jr, Henriques GE, Nóbilo MA, Mesquita MF. The effect of thermal cycling on the bond strength of low-fusing porcelain to commercially pure titanium and titanium-aluminium-vanadium alloy. Dent Mater 2003; 19:790-796.

24. Kim JY, Pfeiffer P, Niedermeier W. Effect of laboratory procedures and thermocycling on the shear bond strength of resin-metal bonding systems. J Prosthet Dent 2003;90:184-189.

25. Shimoe S, Tanoue N, Yanagida H, Atsuta M, Koizumi H, Matsumura H. Comparative strength of metal-ceramic and metal-composite bonds after extended thermocycling. J Oral Rehabil 2004;31:689-694.

26. Poljak-Guberina R, Catovic A, Jerolimov V, Franz M, Bergman V. The fatigue strength of the interface between Ag-Pd alloy and hydrothermal ceramic. Dent Mater 1999; 15: 417-420.

27. Kheradmandan S, Koutayas SO, Bernhard M, Strub JR. Fracture strength of four different types of anterior 3 unit bridges after thermo-mechanical fatigue in the dual-axis chewing simulator. J Oral Rehabil 2001;28:361-369.

28. Koutayas SO, Kern M, Ferraresco F, Strub JR. Influence of design and mode of loading on the fracture strength of all-ceramic resin-bonded fixed partial dentures: an in vitro study in a dual-axis chewing simulator. J Prosthet Dent 2000;83:540-547.

29. Mhaske Prasad N, Nadgere Jyoti B, Ram Sabita M. A Comparative evaluation of shear bond strength of porcelain fused to metal substructure fabricated using conventional and contemporary techniques: an In vitro study. Int J Med Res Health Sci 2015;4:186-192.

30. Jorgenson MW, Good Kind RJ. Spectrophotometric study of five porcelain shades relative to the dimensions of color, porcelain thickness and repeated firings. J Prosthet Dent 1979; 42:96-105.

31. Nawafleh N, Hatamleh M, Elshiyab S, Mack F. Lithium Disilicate Restorations Fatigue Testing Parameters: A Systematic Review. J Prosthodont 2016;25:116-126.

32. Salazar M SM, Pereira SM, Ccahuana V VZ, Passos SP, Vanderlei AD, Pavanelli CA, Bottino MA. Shear bond strength between metal alloy and a ceramic system, submitted to different thermocycling immersion times. Acta Odontol Latinoam 2007;20:97-102.

33. De Melo RM, Travassos AC, Neisser MP. Shear bond strengths of a ceramic system to alternative metal alloys. J Prosthet Dent 2005;93:64-69.
34. Quante K, Ludwig K, Kern M. Marginal and internal fit of metal-ceramic crowns fabricated with a new laser melting technology. Dent Mater 2008;24:1311-1315.

35. Geminiani A, Lee H, Feng C, Ercoli C. The influence of incisal veneering porcelain thickness of two metal ceramic crown systems on failure resistance after cyclic loading. J Prosthet Dent 2010;103:275-282.

36. Roberts HW, Berzins DW, Moore BK, Charlton DG. Metal-ceramic alloys in dentistry: a review. J Prosthodont 2009;18:188-194.

37. Sakaguchi RL, Powers JM. Craig's restorative dental materials, 13th ed.; Elsevier Mosby: Philadelphia, PA, USA. 2012: 199-251.

38. Kim B, Zhang Y, Pines M, Thompson VP. Fracture of porcelain-veneered structures in fatigue. J Dent Res 2007; 86: $142-146$.

39. Sánchez Egea AJ, Martynenko V, Martínez Krahmer D, López de Lacalle LN, Benítez A, Genovese G. On the cutting performance of segmented diamond blades when dry-cutting concrete. Mater 2018; 11: E 264.

40. Oliveira de Vasconcellos LG, Silva LH, Reis de-Vasconcellos LM, Balducci I, Takahashi FE, Bottino MA. Effect of airborne-particle abrasion and mechanic-thermal cycling on the flexural strength of glass ceramic fused to gold or cobalt chromium alloy. J Prosthodont 2011;20:553-560.

41. Oyafuso DK, Ozcan M, Bottino MA, Itinoche MK. Influence of thermal and mechanical cycling on the flexural strength of ceramics with titanium or gold alloy frameworks. Dent Mater 2008;24:351-356.

42. Della Bona A, Van Noort R. Shear vs. tensile bond strength of resin composite bonded to ceramic. J Dent Res1995; 74:1591-1596.

43. Haselton DR, Diaz-Arnold AM, Dunne JT Jr . Shear bond strengths of 2 intraoral porcelain repair systems to porcelain or metal substrates. J Prosthet Dent 2001;86:526-531.

44. De Vasconcellos LG, Buso L, Lombardo GH, Souza RO, Nogueira L Jr, Bottino MA, Ozcan M. Opaque layer firing temperature and aging effect on the flexural strength of ceramic fused to cobalt-chromium alloy. J Prosthodont 2010;19:471-477.

45. Itinoche KM, Ozcan M, Bottino MA, Oyafuso DK. Effect of mechanical cycling on the flexural strength of densely sintered ceramics. Dent Mater 2006;22:1029-1034.

46. Stewardson DA, Shortall AC, Marquis PM. The effect of clinically relevant thermocycling on flexural properties of endodontic post materials. J Dent 2010; 38:437-442. 
47. Heintza SD, Eser A, Monreal D, Rousson V. Using a chewing simulator for fatigue testing of metal ceramic crowns. J Mechan Behav Biomed Mater 2016:1-35.

48. Wang H, Feng Q, Li N, Xu S. Evaluation of metal-ceramic bond characteristics of three dental Co-Cr alloys prepared with different fabrication techniques.J Prosthet Dent 2016; 116:916-923.

49. Fischer J, Zbaren C, Stawarczyk B, Hammerle CH. The effect of thermal cycling on metal-ceramic bond strength. J Dent 2009;37:549-553.

50. Vojdani M, Shaghaghian S, Khaledi A, Adibi S. The effect of thermal and mechanical cycling on bond strength of a ceramic to nickel-chromium(Ni-Cr)and cobalt-chromium (Co-Cr)alloys. Indian J Dent Res 2012; 23(4):509-513.

51. Antanasova M, Kocjan A, Kovac J, Žužek, B, Jevnikar P. Influence of thermo-mechanical cycling on porcelain bonding to cobalt-chromium and titanium dental alloys fabricated by casting, milling, and selective laser melting. J Prosthodont Res 2018; 62(2): 184-194.

52. Trindade FZ, Anami LC, Da Costa Lima J M, Oliveira de Vasconcellos LG, Balducci I, Junior LN, Bottino MA. The effect of a bonding agent and thermomechanical cycling on the bond strength of a glass-ceramic to gold and cobaltchromium alloys. Appl Adhes Scien 2014;16:1-12.

53. Suleiman SH, Vult von Steyern P. Fracture strength of porcelain fused to metal crowns made of cast, milled or laser-sintered cobalt chromium. Acta Odontol Scand 2013;71:1280-1289.

54. Papazoglou E, Brantley WA. Porcelain adherence vs force to failure for palladium-gallium alloys: a critique of metalceramic bond testing. Dent Mater 1998 ;14:112-119. 